Article

\title{
Preparation of Highly Dispersed Reduced Graphene Oxide Modified with Carboxymethyl Chitosan for Highly Sensitive Detection of Trace Cu(II) in Water
}

\author{
Sheng Chen ${ }^{1, *,+}{ }^{+}$, Rui Ding ${ }^{2,+}$, Xiuling $\mathrm{Ma}^{3}{ }^{3}$, Liqun Xue ${ }^{1}$, Xiuzhu Lin ${ }^{1}$, Xiaoping Fan ${ }^{2}$ \\ and Zhimin Luo ${ }^{4, *}$ \\ 1 School of Ocean Science and Biochemistry Engineering, Fuqing Branch of Fujian Normal University, \\ 1 Longjiang Road, Fuqing 350300, China; liqunxue@163.com (L.X.); linxiuzhu1030@163.com (X.L.) \\ 2 College of Environmental Science and Engineering, Fujian Normal University, 8 Shangsan Road, \\ Fuzhou 350007, China; rding@iue.ac.cn (R.D.); fanxiaopingfxp@163.com (X.F.) \\ 3 College of Chemistry and Chemical Engineering, Fujian Normal University, 8 Shangsan Road, \\ Fuzhou 350007, China; mx1502@163.com \\ 4 Jiangsu Key Laboratory for Organic Electronics \& Information Displays and Institute of Advanced \\ Materials (IAM), Nanjing University of Posts and Telecommunications, Nanjing 210046, China \\ * Correspondence: chensheng@fjnu.edu.cn (S.C.); iamzmluo@njupt.edu.cn (Z.L.); \\ Tel.: +86-591-8343-2894 (S.C.) \\ + These authors contributed equally to this work.
}

Academic Editor: Frank Wiesbrock

Received: 31 January 2016; Accepted: 7 March 2016; Published: 1 April 2016

Abstract: In this article, reduced graphene oxide (RGO)/carboxymethyl chitosan (CMC) composites (RGO/CMC) were synthesized by a hydrothermal method through in-situ reduction and modification of graphene oxide (GO) in the presence of CMC. An electrochemical sensor for the determination of $\mathrm{Cu}$ (II) by differential pulse anodic stripping voltammetry (DPASV) was constructed by an electrode modified with RGO/CMC. The fabricated electrochemical sensor shows a linear range of $0.02-1.2 \mu \mathrm{mol} \cdot \mathrm{L}^{-1}$, a detection limit of $3.25 \mathrm{nmol} \cdot \mathrm{L}^{-1}(\mathrm{~S} / \mathrm{N}=3)$ and a sensitivity of $130.75 \mu \mathrm{A} \cdot \mu \mathrm{mol} \cdot \mathrm{L}^{-1} \cdot \mathrm{cm}^{-2}$, indicating the sensor has an excellent detection performance for $\mathrm{Cu}(\mathrm{II})$.

Keywords: graphene; carboxymethyl chitosan; sensor; differential pulse anodic stripping voltammetry; $\mathrm{Cu}(\mathrm{II})$

\section{Introduction}

Copper is an essential element for human beings and plays an important role in various physiological processes at trace level [1,2]. However, due to its toxicity and non-degradation, the contamination of natural water by copper from mining, metal smelting and machinery manufacturing has become serious and attracted more attention $[3,4]$. The excessive copper intake from food chain can interact with lipid hydroxyperoxides, thereby disrupting cellular functions and causing extremely negative health diseases, such as Wilson's disease and kidney damage [5-8]. Therefore, real-time, rapid and sensitive detection of $\mathrm{Cu}$ (II) in water environment is of significance [9]. Until now, there have been many detection methods for $\mathrm{Cu}(\mathrm{II})$, including flame atomic absorption spectrometry (AAS), ultraviolet-visible spectroscopy (UV-Vis), atomic fluorescence spectrometry (AFS) and inductively coupled plasma mass spectrometry (ICP-MS) [10]. Nevertheless, the tedious pretreatments like enrichment and extraction, and the high cost for these methods cannot meet the requirements of development of detecting heavy metal ion. Electrochemical analysis has become an ideal method for detecting metal ions in water due to the easy to transport apparatus, high sensitivity, fast response and low cost [11-13]. 
Graphene, the basic unit of carbonaceous materials, has been reported as an outstanding and promising material for the fabrication of electrochemical sensors due to its unique nanostructure, extraordinary electronic transport properties, excellent electrocatalytic activities and large surface area [14-16]. For instance, an electrochemical sensor fabricated by a gold electrode modified with graphene for the determination of $\mathrm{Cu}$ (II) and $\mathrm{Pb}$ (II) shows high sensitivity, good reusability and repeatability [17]. Wonsawat et al. [18] developed a bismuth-modified graphene-carbon paste electrode for detecting $\mathrm{Cd}(\mathrm{II})$ and $\mathrm{Pb}(\mathrm{II})$ in the automated flow system, and the detection limits reached 0.07 and $0.04 \mu \mathrm{g} \cdot \mathrm{L}^{-1}$, respectively. However, the van der Waals and $\pi-\pi$ stacking interactions between adjacent graphene sheets make them easy to agglomerate, which weakens the advantage of large surface area of graphene and limits its applications [19]. Chitosan, extracted from outer shells of shrimps, carbs and lobsters, was widely used for electrochemical determinations of metals ions [7]. Carboxymethyl chitosan (CMC) is a water-soluble and biodegradable derivate of chitosan, containing a large number of hydroxyl and carboxyl groups, which can make carbon nanomaterials such as carbon nanotube highly dispersed in the aqueous solution [20].

In this study, we prepared a functional nanocomposite through chemical modification of reduced graphene oxide with CMC. GO was reduced to RGO and in-situ modified with CMC in the procedure of synthesis. The chemical functionalization of RGO by CMC can efficiently inhibit the aggregation of RGO nanosheet in aqueous solution. RGO/CMC was used for modifying glassy carbon electrode (GCE) to detect $\mathrm{Cu}$ (II) in water by differential pulse anodic stripping voltammetry (DPASV). The results show that the electrochemical sensor has a linear range of $0.02-1.2 \mu \mathrm{mol} \cdot \mathrm{L}^{-1}$, a low detection limit of $3.25 \mathrm{nmol} \cdot \mathrm{L}^{-1}(\mathrm{~S} / \mathrm{N}=3)$, high sensitivity of $130.75 \mu \mathrm{A} \cdot \mu \mathrm{mol} \cdot \mathrm{L}^{-1} \mathrm{~cm}^{-2}$, high selectivity and excellent reproducibility with the relative standard deviation (RSD) of $0.55 \%$. Because RGO/CMC has high affinity towards metal ions and good conductivity, it has much potential for applications in the electrochemical sensors to detect trace $\mathrm{Cu}(\mathrm{II})$ in the water environment.

\section{Materials and Methods}

\subsection{Chemical Reagents}

Carboxymethyl chitosan (carboxylation degrees $\geqslant 60 \%$ ) was purchased from Zhejiang golden shell biological chemical Co. Ltd. (Hangzhou, China). Graphite powder was purchased from Aladdin (Shanghai, China). Hydrazine hydrate (50\%), potassium ferricyanide and glacial acetic acid (100\%) were purchased from Guoyao Chemicals Co. Ltd. (Shanghai, China). Nafion (5\%) was purchased from Sigma-Aldrich (St. Louis, MO, USA).

\subsection{Instruments and Measurements}

The electrochemical experiments were performed on a CHI660D electrochemical workstation (CH Instrumental Co., Shanghai, China). The morphology of RGO/CMC was observed by transmission electron microscopy (TEM, JEM-2010F UHR, JEOL Ltd., Tokyo, Japan). The spectral properties were characterized by ultraviolet-visible spectroscopy (UV-Vis, TU-1800PC, Puxi Tongyong Instrument, Beijing, China), Fourier-transform infrared spectroscopy (FT-IR, Nicolet-380, Thermo Electron Co., Waltham, MA, USA), Raman spectra instrument (Olympus FV1000, Olympus Co., Tokyo, Japan). The surface property of RGO/CMC colloidal aqueous solution was studied by Zeta potential analyzer (Zetasizer Nano, Malvern Instruments Ltd., Worcestershire, UK). The component percentage of sample were measured through thermal gravimetric analysis (TGA, SDTA851e, Mettler-Toledo Co., Zurich, Switzerland) with a heating rate of $10{ }^{\circ} \mathrm{C} \cdot \mathrm{min}^{-1}$ using pure nitrogen as a carrier gas. The crystal structures of GO and RGO/CMC were characterized by X-ray diffraction (XRD, X'Pert, Philips Co., Eindhoven, The Netherlands). 


\subsection{Preparation of RGO/CMC Composite}

GO was prepared by a modified Hummers method (See Supplementary Information). Two milliliters of GO $\left(2 \mathrm{mg} \cdot \mathrm{mL}^{-1}\right), 2 \mathrm{~mL}$ of CMC $\left(3 \mathrm{mg} \cdot \mathrm{mL}^{-1}\right)$ and $16 \mathrm{~mL}$ of deionized water were well mixed by ultrasonication for $2 \mathrm{~h}$. Then, $1.4 \mu \mathrm{L}$ of hydrazine hydrate were added to the solutions and the mixture was heated at $90{ }^{\circ} \mathrm{C}$ for $1.5 \mathrm{~h}$. The reacted solution was filtered by microfiltration membrane (aperture $<0.22 \mu \mathrm{m}$ ) and washed by deionized water for at least three times. Finally, the as-prepared $\mathrm{RGO} / \mathrm{CMC}$ sheet was dried at $60^{\circ} \mathrm{C}$ for further use.

\subsection{RGO/CMC/Nafion Modified GCE}

As shown in Scheme 1, the fabrication of $\mathrm{Cu}$ (II) sensor was completed as briefly described in the following.

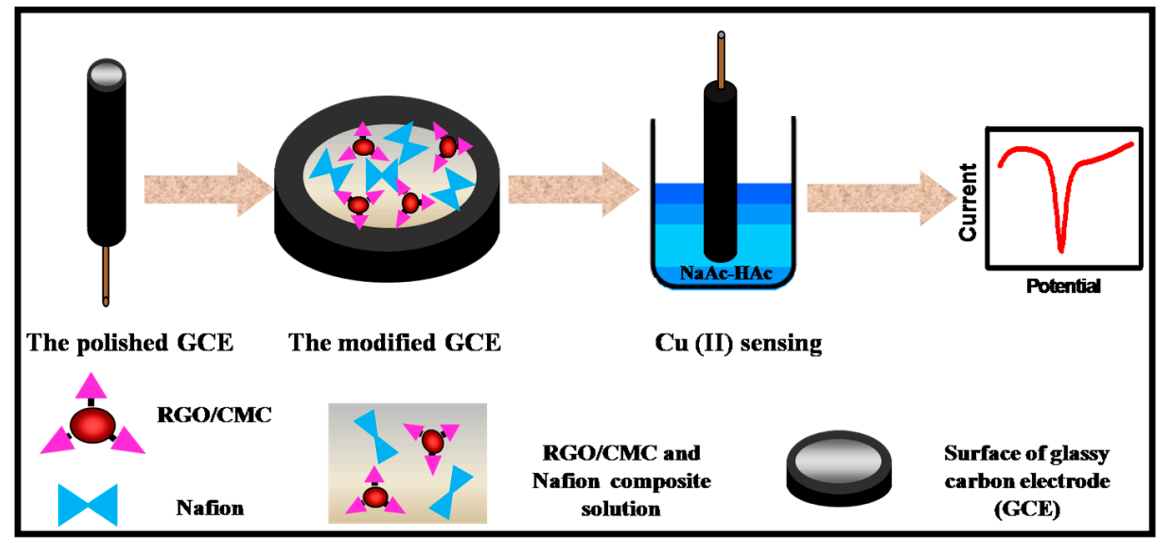

Scheme 1. Schematic illustration of RGO/CMC/Nafion modified GCE for Cu(II) sensing.

\subsubsection{Fabrication of $\mathrm{Cu}(\mathrm{II})$ Sensor by $\mathrm{RGO} / \mathrm{CMC} / \mathrm{Nafion}$}

Prior to the modification of electrode, the bare GCE was sequentially polished with 1.0, 0.3 and $0.05 \mu \mathrm{m}$ alumina powder $\left(\alpha-\mathrm{Al}_{2} \mathrm{O}_{3}\right)$ and followed by ultrasonically rinsing with ethanol and deionized water in turn.

The prepared RGO/CMC was dispersed in deionized water by ultrasonicaction. RGO/CMC/Nafion suspension was obtained by mixing the RGO/CMC solution $\left(1 \mathrm{mg} \cdot \mathrm{mL}^{-1}\right)$ and Nafion solution $(0.5 \%)$ with volume ratio of 1:1 through ultrasonication.

Then, RGO/CMC/Nafion was casted on the surface of GCE through dropping a certain amount of mixture suspension.

\subsubsection{Electrochemical Analysis}

A standard three-electrode system connected to the $\mathrm{CHI} 660 \mathrm{E}$ was used for $\mathrm{Cu}$ (II) detection. The RGO/CMC/Nafion modified GCE acted as the working electrode, an $\mathrm{Ag} / \mathrm{AgCl}$ (saturated with $\mathrm{KCl}$ ) as the reference electrode and a platinum wire as the counter electrode. The experiment was performed in a HAc-NaAc buffer solution $(\mathrm{pH}=4.4)$ containing $\mathrm{Cu}(\mathrm{II})$. The electrochemical response of RGO/CMC/Nafion modified GCE was measured by DPASV with a scanning potential range from -0.50 to $0.40 \mathrm{~V}$ with a step voltage of $4 \mathrm{mV}$, a pulse amplitude of $50 \mathrm{mV}$, a pulse width of $0.06 \mathrm{~s}$, and a pulse separation of $0.20 \mathrm{~s}$.

The RGO/CMC/Nafion modified GCE was accumulated for $360 \mathrm{~s}$ by DPASV with stirring under the constant potential of $-0.6 \mathrm{~V}$. Afterwards, $i-t$ method was used for restoring its activity by removing the sediment that adsorbed on the surface of the modified GCE at the potential of $0.60 \mathrm{~V}$. 


\section{Results and Discussion}

\subsection{Characterizations of $R G O / C M C$}

As shown in Figure 1a, large RGO/CMC nanosheets are observed in the TEM image without agglomeration. FT-IR spectrum of RGO/CMC (Figure 1b) indicates that GO has been effectively reduced as the absorption intensity of the hydroxyl $\left(3428 \mathrm{~cm}^{-1}\right)$ and epoxy $\left(1047 \mathrm{~cm}^{-1}\right)$ were evidently decreased [21]. Furthermore, the new absorption peak appearing at $2925 \mathrm{~cm}^{-1}$ ascribed to the methyl and methylene of CMC, confirms the successful modification of CMC on the surface of RGO [22,23].
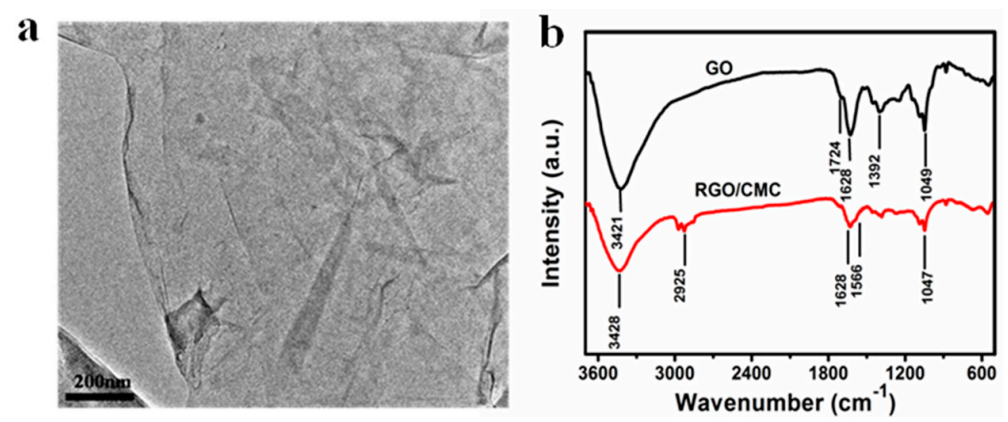

Figure 1. (a) A TEM image of RGO/CMC; (b) FT-IR spectra of GO and RGO/CMC.

Figure 2a shows UV-Vis absorption spectra of GO, RGO and RGO/CMC. The spectrum of GO presents two characteristic features, a maximum peak at $242 \mathrm{~nm}$ assigned to $\pi \rightarrow \pi^{*}$ transitions of aromatic $\mathrm{C}-\mathrm{C}$ bonds and a shoulder peak around $301 \mathrm{~nm}$ assigned to $\mathrm{n} \rightarrow \pi^{*}$ transitions of $\mathrm{C}=\mathrm{O}$ bonds [24]. After the reduction of GO, its maximum peak at $230 \mathrm{~nm}$ redshifts to $254 \mathrm{~nm}$ for RGO and $267 \mathrm{~nm}$ for RGO/CMC. Compared with GO, the obvious red-shift of maximum peak of the spectrum of RGO/CMC is due to the reduction of GO and thus restoration of electron [25]. The shoulder peak assigned to carbonyl bond absorption is no longer present because of its chemical reduction by hydrazine hydrate [26-29].
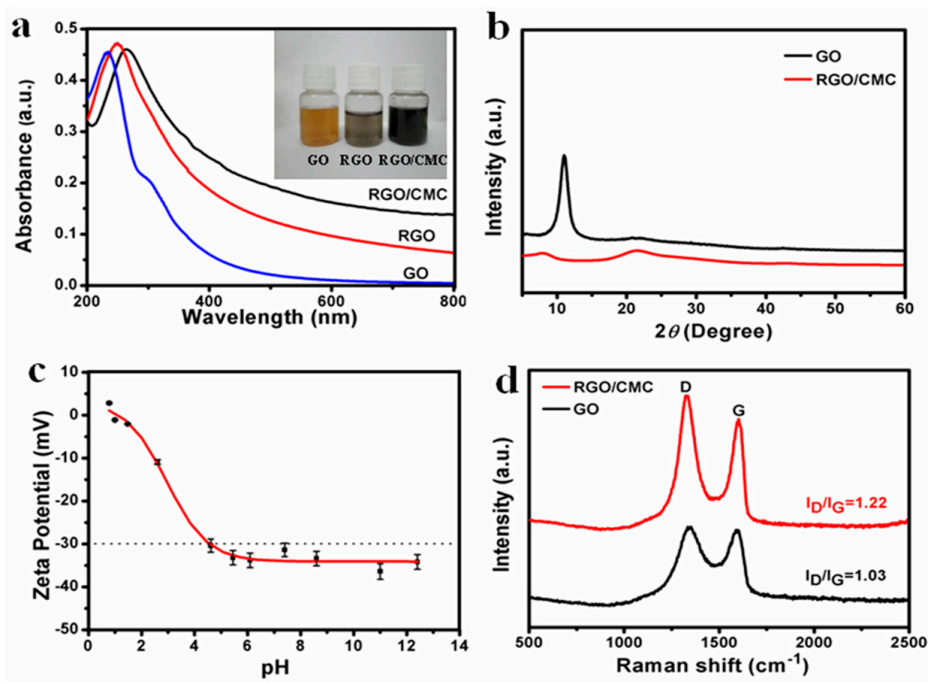

Figure 2. (a) UV absorption spectra of RGO/CMC, RGO and GO; (b) XRD diffraction patterns of GO and RGO/CMC; (c) Zeta potential of RGO/CMC aqueous solution; (d) Raman spectra of GO and $\mathrm{RGO} / \mathrm{CMC}$.

As seen in the XRD patterns (Figure $2 b$ ) of the GO and RGO/CMC, the pattern of GO exhibits a single peak at $11.05^{\circ}$ corresponding to an interlayer $d$ spacing of $8 \AA$, indicating the high degree of 
oxidation of GO [30]. Compared with GO, the XRD pattern of RGO/CMC shows a broad peak around at $22.35^{\circ}(d=4.16 \AA)$. The breaking of the crystal structural integrity is the key factor for widening of the peak [31]. The restoration of electron may leads to the migration of peak [25]. Raman spectra of GO and RGO/CMC (Figure 2d) display two strong bands roughly at $\sim 1346 \mathrm{~cm}^{-1}$ (D band) and at $\sim 1590 \mathrm{~cm}^{-1}$ ( $\mathrm{G}$ band) associated with the imperfection of the disordered $\mathrm{sp}^{2}$ bond structure of carbon materials and the mode of highly ordered pyrolytic graphite, respectively. Raman characterization indicates the main graphene structure of graphene is conserved in $\mathrm{RGO} / \mathrm{CMC}$ composite [32]. The relative intensity ratio of $\mathrm{D} / \mathrm{G}$ bands $\left(I_{\mathrm{D}} / \mathrm{I}_{\mathrm{G}}\right)$ of the GO and $\mathrm{RGO} / \mathrm{CMC}$ are calculated to be 1.03 and 1.22 , respectively, indicating a decrease in the average size of the $\mathrm{sp}^{2}$ domains after chemical reduction [33].

Zeta potential was used to evaluate the stability of colloidal solution. The higher the absolute value of Zeta potential is, the more stability the nanomaterials have. As shown in Figure 2c, the Zeta potential of $\mathrm{RGO} / \mathrm{CMC}$ changes from 5 to $-35 \mathrm{mV}$ in the $\mathrm{pH}$ value range from 1.0 to 12.5 . When the $\mathrm{pH}$ is between 4.5 and 12.5, the absolute value of Zeta potential is above $30 \mathrm{mV}$, illustrating the good stability of $\mathrm{RGO} / \mathrm{CMC}$ in the $\mathrm{pH}$ value range from 4.5 to 12.5 . According to the relevant literature [34,35], RGO can keep stable in alkaline environment $(\mathrm{pH}>8)$, while CMC modified RGO can keep stable in a wider range of $\mathrm{pH}(\mathrm{pH}>4.5)$.

Figure 3 shows the thermal gravity analysis-differential thermal gravity (TG-DTG) curves of $\mathrm{CMC}$ and RGO/CMC. When the temperature rose from room temperature to $800^{\circ} \mathrm{C}$, a broad peak at $334.1{ }^{\circ} \mathrm{C}$ appeared in the DTG curve of CMC, corresponding to the $45 \%$ of mass loss step of TG curve assigned to the depolymerization and thermal decomposition of indican units in $\mathrm{CMC}$ at the temperature range of $250-400{ }^{\circ} \mathrm{C}$ [36]. In addition to the agravic peak at $334.1^{\circ} \mathrm{C}$, another obvious peak at $186.4^{\circ} \mathrm{C}$ can also be observed from the DTG curve of RGO/CMC, indicating the decomposition of $\mathrm{CMC}$ in $\mathrm{RGO} / \mathrm{CMC}$ [37]. When the temperature reaches to $500{ }^{\circ} \mathrm{C}$, the $\mathrm{TG}$ curve of $\mathrm{RGO} / \mathrm{CMC}$ changes slowly, and the residual mass loss of about $10 \%$ is mainly owing to the thermal reduction of graphene oxide. TG and DTG characterizations confirm that there is about $15 \mathrm{wt} \%$ of CMC on the surface of RGO.
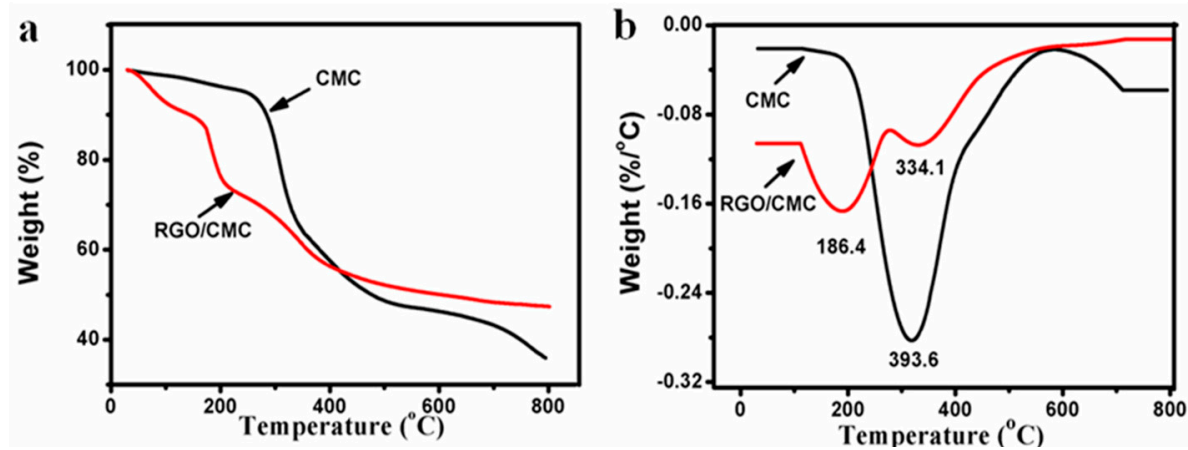

Figure 3. (a) TG and (b) DTG curves of CMC and RGO/CMC.

\subsection{Electrochemical Detection of $\mathrm{Cu}(\mathrm{II})$}

For comparison, electrochemical experiments of bare GCE, GCE/Nafion and GCE modified with RGO/CMC/Nafion were carried out by DPASV under the same experimental conditions. Figure 4 depicts the detection performances of electrodes for $1.0 \mu \mathrm{mol} \cdot \mathrm{L}^{-1} \mathrm{Cu}(\mathrm{II})$ in $0.1 \mathrm{~mol} \cdot \mathrm{L}^{-1} \mathrm{NaAc}-\mathrm{HAc}$ $(\mathrm{pH}=4.4)$. After accumulation for $360 \mathrm{~s}$, the anodic peak current response of the RGO/CMC/Nafion modified GCE (c in Figure 4) is higher than bare GCE (a in Figure 4) and GCE/Nafion (b in Figure 4), indicating RGO/CMC can dramatically improve electroanalytical current response for $\mathrm{Cu}(\mathrm{II})$. According to the research of Khomyakov et al. [38], the interaction and charge transfer between graphene and metal ions is one of the main reasons for sensitivity of modified electrode. The detection of $\mathrm{Cu}(\mathrm{II})$ by the $\mathrm{RGO} / \mathrm{CMC} /$ Nafion modified GCE may be by two steps and the reaction equations are shown below: 
(1) The enrichment process.

$(\mathrm{Cu}(\mathrm{II}))$ sol. $+(\mathrm{M})$ surf. $-(\mathrm{Cu}(\mathrm{II})-\mathrm{M})$ ads. $(\mathrm{Cu}(\mathrm{II})-\mathrm{M})$ ads. $+2 \mathrm{e}^{-}-(\mathrm{Cu}(0)-\mathrm{M})$ ads.

(2) The dissolution process.

$(\mathrm{Cu}(0)-\mathrm{M})$ ads. $-(\mathrm{Cu}(\mathrm{II}))$ sol. $+(\mathrm{M})$ surf. $+2 \mathrm{e}^{-}$

$\mathrm{M}$ in the equation stands for RGO/CMC/Nafion.

During the enrichment process, the chelated $\mathrm{Cu}$ (II) will be reduced to elementary copper at the working potential of $0.60 \mathrm{~V}$. After enrichment, with the potential changes from -0.50 to $0.40 \mathrm{~V}$, the copper dissolves and a sensitive anodic stripping peak can be seen at $0.06 \mathrm{~V}$.

The peak potential of RGO/CMC/Nafion modified GCE has a slightly negative shift of $-0.06 \mathrm{~V}$ ( $\mathrm{c}$ in Figure 4) as compared to GCE (a in Figure 4) and Nafion/GCE (b in Figure 4), which may due to the accelerated electron transfer process by the functionalization of RGO/CMC [39]. The higher anodic peak current response can be attributed to the function of $\mathrm{RGO} / \mathrm{CMC}$, which can offer more sites to chelate $\mathrm{Cu}$ (II) for improving current response because of abundant carboxyl groups in CMC and RGO.

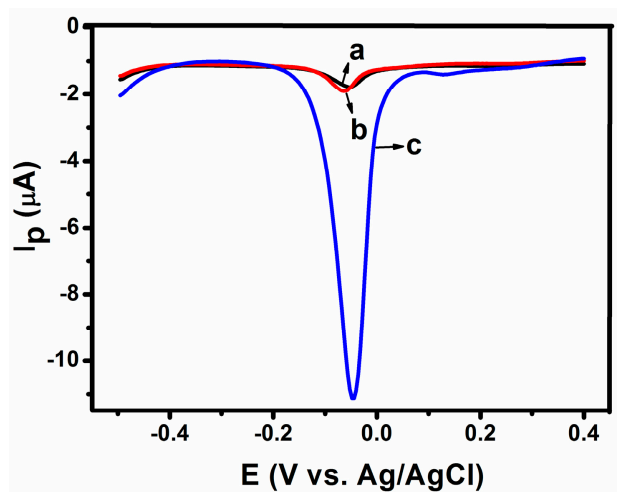

Figure 4. DPASV for $1.0 \mu \mathrm{mol} \cdot \mathrm{L}^{-1} \mathrm{Cu}$ (II) in $0.1 \mathrm{M} \mathrm{NaAc}-\mathrm{HAc}(\mathrm{pH}=4.4)$ with different electrodes: (a) Bare GCE; (b) Nafion/GCE; and (c) RGO/CMC/Nafion/GCE. Detection conditions: amplitude of $0.05 \mathrm{~V}$, pulse width of $0.06 \mathrm{~s}$, and pulse period of $0.20 \mathrm{~s}$.

\subsection{Optimization of Detection Conditions}

Table 1 shows the effect of various supporting electrolytes, including acid solution, alkaline solution and neutral solution, on different pulse anodic stripping peak current of the $\mathrm{Cu}$ (II) on $\mathrm{RGO} / \mathrm{CMC} / \mathrm{Nafion} / \mathrm{GCE}$. It is found that the stripping peak current in NaAc-HAc $\left(0.1 \mathrm{~mol} \cdot \mathrm{L}^{-1}\right)$ is the highest, followed by the hydrochloric acid solution, sulfuric acid, potassium chloride, and no response in the sodium hydroxide solution. The electrochemical responses of $\mathrm{Cu}(\mathrm{II})$ in different $\mathrm{pH}$ values of NaAc-HAc $\left(0.1 \mathrm{~mol} \cdot \mathrm{L}^{-1}\right)$ at RGO/CMC/Nafion/GCE were studied by DPASV. As show in Figure 5a, the stripping peak current of the modified GCE increases with the increase of $\mathrm{pH}$ value from 3.6 to 4.4. After that, the peak current decreases with the further increase of $\mathrm{pH}$ value, which is consistent with the results of Table 1 . Consequently, considering the sensitivity and stability of detection, NaAc-HAc $\left(0.1 \mathrm{~mol} \cdot \mathrm{L}^{-1}\right)$ was chosen for this work.

Table 1. Effect of different types of supporting electrolytes on the stripping peak currents.

\begin{tabular}{cc}
\hline Supporting Electrolyte & Stripping Peak Current $(\mu \mathrm{A})$ \\
\hline $\mathrm{KCl}\left(0.1 \mathrm{~mol} \cdot \mathrm{L}^{-1}\right)$ & 0.3670 \\
$\mathrm{NaOH}\left(0.1 \mathrm{~mol} \cdot \mathrm{L}^{-1}\right)$ & No response \\
$\mathrm{H}_{2} \mathrm{SO}_{4}\left(0.1 \mathrm{~mol} \cdot \mathrm{L}^{-1}\right)$ & 0.9271 \\
$\mathrm{HCl}\left(0.1 \mathrm{~mol} \cdot \mathrm{L}^{-1}\right)$ & 1.056 \\
$\mathrm{NaAc}-\mathrm{HAc}$ buffer solution & 1.568 \\
\hline
\end{tabular}



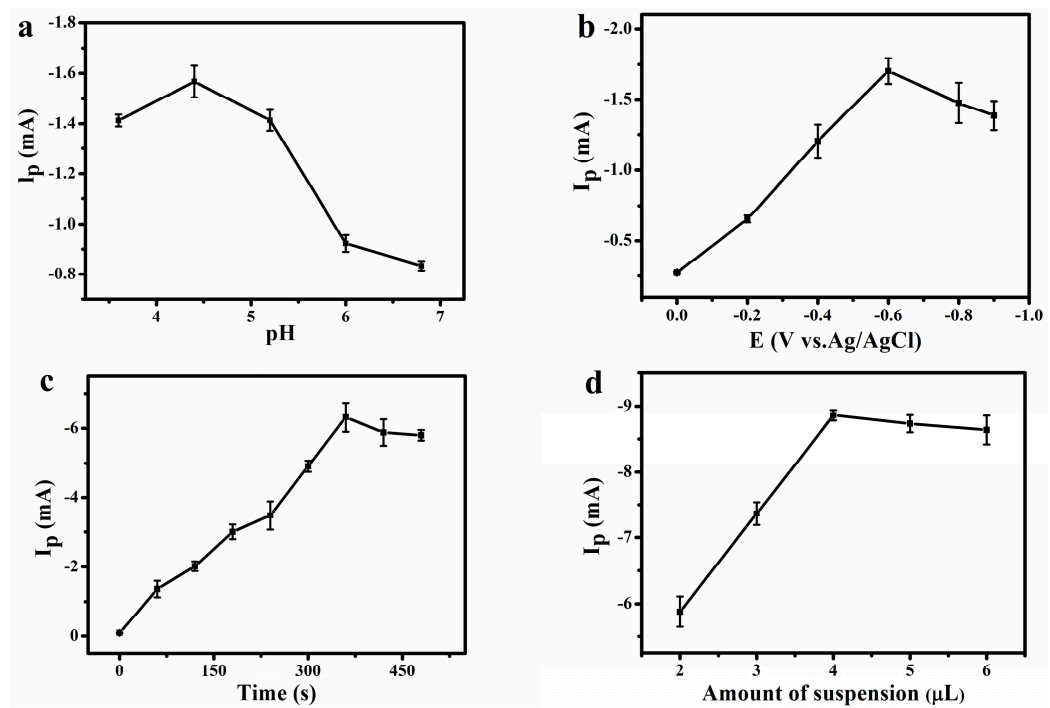

Figure 5. The effect of: (a) pH; (b) accumulation potential; (c) accumulation time; and (d) dosage of $\mathrm{RGO} / \mathrm{CMC} /$ Nafion on the stripping peak current of $1.0 \times 10^{-6} \mathrm{~mol} \cdot \mathrm{L}^{-1} \mathrm{Cu}(\mathrm{II})$.

The influences of accumulation potential, accumulation time and dosage were also investigated. The effect of accumulation potential on peak current is illustrated in Figure $5 \mathrm{~b}$. The peak current increases rapidly with the decrease of accumulation potential from 0.0 to $-0.60 \mathrm{~V}$. It can be explained that $\mathrm{Cu}$ (II) is able to be reduced at more negative potential. However, with the further decrease of accumulation potential from -0.60 to $-0.90 \mathrm{~V}$, the peak current decreases gradually. Parts of the active sites on the modified electrode surface are occupied by some other ions in the negative potential, leading to obstruction of the determination of $\mathrm{Cu}(\mathrm{II})$. Figure $5 \mathrm{c}$ displays the influence of accumulation time for stripping peak currents. When the accumulation time is $360 \mathrm{~s}$, the response current is the highest because the adsorption of $\mathrm{Cu}$ (II) on the surface of modified electrodes has reached saturation [40]. The addition of RGO/CMC/Nafion was studied in the range of 2-6 $\mu \mathrm{L}$. As shown in Figure $5 \mathrm{~d}$, when the dosage of $\mathrm{RGO} / \mathrm{CMC} /$ Nafion is $4 \mu \mathrm{L}$, the response current is the highest. When the dosage continue to increases, the current decrease, which is mainly due to the increase of film thickness obstructing the electron transfer process between $\mathrm{Cu}(\mathrm{II})$ and electrode.

The repeated use of RGO/CMC/Nafion modified electrode was examined by $i$ - $t$ measurement. Table 2 shows the change of peak currents after repeated measurement of $1.0 \times 10^{-6} \mathrm{~mol} \cdot \mathrm{L}^{-1} \mathrm{Cu}$ (II) for using the same RGO/CMC/Nafion modified electrode ten times. The relative standard deviation is $0.55 \%$, indicating the RGO/CMC/Nafion modified GCE has an excellent reproducibility for the detection of $\mathrm{Cu}(\mathrm{II})$.

Table 2. $i_{p}$ of the RGO/CMC/Nafion modified GCE responding to the $1.0 \times 10^{-6} \mathrm{~mol} \cdot \mathrm{L}^{-1}$ of $\mathrm{Cu}(\mathrm{II})$.

\begin{tabular}{ccccccccccc}
\hline $\mathbf{N}$ & $\mathbf{1}$ & $\mathbf{2}$ & $\mathbf{3}$ & $\mathbf{4}$ & $\mathbf{5}$ & $\mathbf{6}$ & $\mathbf{7}$ & $\mathbf{8}$ & $\mathbf{9}$ & $\mathbf{1 0}$ \\
\hline$i_{\mathrm{p}}(\mu \mathrm{A})$ & 0.723 & 0.711 & 0.718 & 0.714 & 0.719 & 0.719 & 0.722 & 0.716 & 0.721 & 0.723 \\
\hline
\end{tabular}

\subsection{Anti-Interference of RGO/CMC/Nafion Modified GCE}

Since there are still some other common metal ions in water, the detection of the identification performance of RGO/CMC/Nafion modified GCE is necessary. For practical purposes, $1.0 \times 10^{-6} \mathrm{~mol} \cdot \mathrm{L}^{-1} \mathrm{Cu}$ (II) solutions with different metal ions commonly presenting in natural water were used to examine the anti-interference of RGO/CMC/Nafion modified electrode. As shown in Table 3, the response current of the RGO/CMC/Nafion modified GCE changes within less than $\pm 5 \%$ with the addition of the interfering ions. Therefore, the RGO/CMC modified GCE is suitable for the detection of $\mathrm{Cu}(\mathrm{II})$ in real water samples after some pretreatments. 
Table 3. $\left(i_{\mathrm{o}}-i_{\mathrm{p}}\right) / i_{\mathrm{p}}$ of sensor for $1.0 \times 10^{-6} \mathrm{~mol} \cdot \mathrm{L}^{-1} \mathrm{Cu}(\mathrm{II})$ in the presence of other metal ions.

\begin{tabular}{ccc}
\hline Concentration $\mathbf{( m o l} \cdot \mathbf{~ L}^{-1}$ ) & Species & Interference (\%) \\
\hline \multirow{3}{*}{$5.0 \times 10^{-4}$} & $\mathrm{Na}^{+}$ & -3.5 \\
& $\mathrm{~K}^{+}$ & -2.9 \\
& $\mathrm{Ca}^{2+}$ & -4.8 \\
& $\mathrm{Mg}^{2+}$ & -1.5 \\
\hline \multirow{2}{*}{$1.0 \times 10^{-4}$} & $\mathrm{Mn}^{2+}$ & -3.1 \\
& $\mathrm{Cd}^{2+}$ & -4.6 \\
\hline \multirow{2}{*}{$2.0 \times 10^{-5}$} & $\mathrm{~Pb}^{2+}$ & -4.9 \\
& $\mathrm{Zn}^{2+}$ & -4.4 \\
\hline
\end{tabular}

\subsection{Detection Limit of Cu(II) with RGO/CMC/Nafion Modified GCE}

Figure 6 shows the stripping voltammograms under the optimized conditions with the concentration of $\mathrm{Cu}$ (II) from 0.02 to $1.2 \mu \mathrm{mol} \cdot \mathrm{L}^{-1}$ and the corresponding calibration curve of the stripping peak current versus the concentrations of $\mathrm{Cu}(\mathrm{II})$ (inset). The RGO/CMC/Nafion modified electrode shows good detection limit of $3.25 \mathrm{nmol} \cdot \mathrm{L}^{-1}(\mathrm{~S} / \mathrm{N}=3)$ and a sensitivity of $130.75 \mu \mathrm{A} \cdot \mu \mathrm{mol} \mathrm{L}-1 \cdot \mathrm{cm}^{-2}$. The limit of detection (LOD) was calculated as follows: $\mathrm{LOD}=3 \mathrm{~S} / \mathrm{m}$, where $S$ is standard deviation of current value, $m$ is sensitivity, which is the slope of the linear equation. Comparison of other modified electrodes for the determination of $\mathrm{Cu}(\mathrm{II})$ is given in Table 4 . The present work exhibited better electrochemical analysis performance in detecting trace $\mathrm{Cu}$ (II) with lower detection limit in wide linear range.

Table 4. Comparison of different modified electrodes for detecting $\mathrm{Cu}(\mathrm{II})$.

\begin{tabular}{cccccc}
\hline Modifier & Electrode & Method & $\begin{array}{c}\text { Detection Range } \\
\left(\mu \mathbf{m o l} \cdot \mathbf{L}^{-1}\right)\end{array}$ & $\begin{array}{c}\text { Detection Limit } \\
\left(\mathbf{n m o l} \cdot \mathbf{L}^{-1}\right)\end{array}$ & Ref. \\
\hline Tripeptide (Gly-Gly-His) & GCE & DPSV & $0.1-30$ & 46 & {$[41]$} \\
AMT-g-NGO & CPE & SWASV & $0.1-1.0 \times 10^{5}$ & 40 & {$[42]$} \\
Graphene & Gold electrode & OSWV & $1.5 \times 10^{-3}-0.02$ & $1.5 \pm 0.2$ & {$[17]$} \\
$\begin{array}{c}\text { Propargyl-functionalized ferrocene } \\
\text { Ionic liquid-functionalized orderd }\end{array}$ & Gold electrode & DPV & $1.0 \times 10^{-8}-1.0 \times 10^{-3}$ & $3.4 \times 10^{-6}$ & {$[43]$} \\
mesoporous silica SBA-15 & CPE & DPASV & $0.3-100$ & 10 & {$[44]$} \\
Crosslinked chitosan & CNPE & LSASV & $0.079-16$ & 10 & {$[7]$} \\
Silica & CPE & DPSV & $0.05-0.2$ & 3 & {$[45]$} \\
RGO/CMC & GCE & DPASV & $0.02-1.2$ & 3.25 & Present \\
work \\
\hline
\end{tabular}

DPSV: Differential pulse stripping voltammetry; AMT-g-NGO: 2-amino-5-mercapto-1,3,4-thiadiazole/Nano graphene oxide; CPE: Carbon paste electrode; SWASV: Square wave anodic stripping voltammetry; OSWV: Osteryoung square wave voltammetry; DPV: Different pulse voltammetry; CNPE: Carbon nanotubes past electrode; LSASV: Linear scan anodic stripping voltammetry.

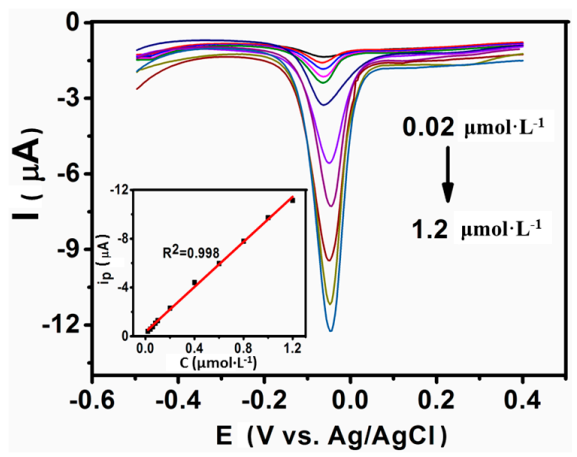

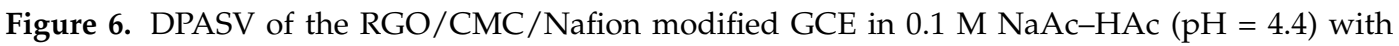
various concentrations of $\mathrm{Cu}$ (II). From top to bottom, the different colors of the curves represent the concentration of $\mathrm{Cu}$ (II) of $0.02,0.04,0.06,0.08,0.1,0.2,0.4,0.6,0.8,1.0$ and $1.2 \mu \mathrm{mol} \cdot \mathrm{L}^{-1}$, respectively. Inset is the calibration curve of the stripping peak currents versus the concentrations of $\mathrm{Cu}(\mathrm{II})$. 


\section{Conclusions}

In this article, water-soluble and highly dispersed RGO/CMC was prepared by the chemical reduction of GO and in-situ modification with CMC. A simple and effective electrochemical sensor for determination of $\mathrm{Cu}(\mathrm{II})$ was constructed by DPASV based on the RGO/CMC/Nafion modified GCE. The RGO/CMC/Nafion modified GCE displays good analytical performance including wide linear range, low detection limit, high sensitivity, good repeatability to $\mathrm{Cu}(\mathrm{II})$ and excellent anti-interference ability towards other interfering metal ions. The fabricated sensor based on RGO/CMC/Nafion is promising in the determination of trace $\mathrm{Cu}(\mathrm{II})$ in real water samples.

Supplementary Materials: Supplementary materials can be found at www.mdpi.com/2073-4360/8/3/78/s1.

Acknowledgments: This work was financially supported by the National Natural Science Foundation of China (21207018).

Author Contributions: Sheng Chen and Zhimin Luo conceived and designed the experiments; Rui Ding wrote the paper; Xiuling Ma analyzed the data; Xiaoping Fan performed the experiments; Liqun Xue and Xiuzhu Lin contributed materials tools.

\section{References}

1. Zhang, J.; Li, B.; Zhang, L.M.; Jiang, H. An optical sensor for Cu (II) detection with upconverting luminescent nanoparticles as an excitation source. Chem. Commun. 2012, 48, 4860-4862. [CrossRef] [PubMed]

2. Liao, Y.; Li, Q.; Yue, Y.; Shao, S.J. Selective electrochemical determination of trace level copper using a salicylaldehyde azine/MWCNTs/Nafion modified pyrolytic graphite electrode by the anodic stripping voltammetric method. RSC Adv. 2015, 5, 3232-3238. [CrossRef]

3. Gupta, V.K.; Singh, L.P.; Singh, R.; Upadhyay, N.; Kaur, S.P.; Sethi, B. A novel copper (II) selective sensor based on dimethyl 4,4'(o-phenylene) bis (3-thioallophanate) in PVC matrix. J. Mol. Liq. 2012, 174, 11-16. [CrossRef]

4. Ding, R.; Luo, Z.M.; Ma, X.L.; Fan, X.P.; Xue, L.Q.; Lin, X.Z.; Chen, S. High sensitive sensor fabricated by reduced graphene oxide/polyvinyl butyral nanofibers for detecting $\mathrm{Cu}$ (II) in water. Int. J. Anal. Chem. 2015. [CrossRef] [PubMed]

5. Cui, S.Q.; Pu, S.Z.; Dai, Y.F. A novel colorimetric sensor based on a diarylethene derivative for selective detection of $\mathrm{Cu}$ (II). Anal. Methods 2015, 7, 3593-3599. [CrossRef]

6. Park, G.J.; Hwang, I.H.; Song, E.J.; Kim, H.; Kim, C. A colorimetric and fluorescent sensor for sequential detection of copper ion and cyanide. Tetrahedron 2014, 70, 2822-2828. [CrossRef]

7. Janegitz, B.C.; Marcolino-Junior, L.H.; Campana-Filho, S.P.; Faria, R.C.; Fatibello-Filho, O. Anodic stripping voltammetric determination of copper (II) using a functionalized carbon nanotubes paste electrode modified with crosslinked chitosan. Sens. Actuators B 2009, 142, 260-266. [CrossRef]

8. Gumpu, M.B.; Sethuraman, S.; Krishnan, U.M.; Rayappan, B.B.R. A review on detection of heavy metal ions in water-An electrochemical approach. Sens. Actuators B 2015, 213, 515-533. [CrossRef]

9. Lin, H.; Li, M.X.; Mihailovič, D. Simultaneous determination of copper, lead, and cadmium ions at a $\mathrm{Mo}_{6} \mathrm{~S}_{9^{-}} \mathrm{I}_{\mathrm{x}}$ nanowires modified glassy carbon electrode using differential pulse anodic stripping voltammetry. Electrochim. Acta 2015, 154, 184-189. [CrossRef]

10. Afkhami, A.; Khoshsafar, H.; Madrakian, T.; Shirzadmehr, A. A new nano-composite electrode as a copper (II) selective potentiometric sensor. J. Iran. Chem. Soc. 2014, 11, 1373-1380. [CrossRef]

11. Cantalapiedra, A.; Gismera, M.J.; Procopio, J.R.; Sevilla, M.T. Electrochemical sensor based on polystyrene sulfonate-carbon nanopowders composite for $\mathrm{Cu}$ (II) determination. Talanta 2015, 139, 111-116. [CrossRef] [PubMed]

12. Li, M.; Gou, H.L.; Al-Ogaidi, I.; Wu, N.Q. Nanostructured sensors for detection of heavy metals: A review. ACS Sustain. Chem. Eng. 2013, 1, 713-723. [CrossRef]

13. Afkhami, A.; Soltani-Felehgari, F.; Madrakian, T.; Ghaedi, T.; Rezaeivala, M. Fabrication and application of a new modified electrochemical sensor using nano-silica and a newly synthesized Schiff base for simultaneous determination of $\mathrm{Cd}^{2+}, \mathrm{Cu}^{2+}$ and $\mathrm{Hg}^{2+}$ ions in water and some foodstuff samples. Anal. Chim. Acta 2013, 771, 21-30. [CrossRef] [PubMed]

14. Kang, X.H.; Wang, J.; Wu, H.; Liu, J.; Aksay, I.A.; Lin, Y.H. A graphene-based electrochemical sensor for sensitive detection of paracetamol. Talanta 2010, 81, 754-759. [CrossRef] [PubMed] 
15. Wei, Y.; Gao, C.; Meng, F.L.; Li, H.H.; Wang, L.; Liu, J.H.; Huang, X.J. $\mathrm{SnO}_{2}$ /reduced graphene oxide nanocomposite for the simultaneous electrochemical detection of cadmium(II), lead(II), copper(II), and mercury(II): An interesting favorable mutual interference. J. Phys. Chem. C 2011, 116, 1034-1041. [CrossRef]

16. Le, T.X.H.; Bechelany, M.; Champavert, J.; Cretin, M. A highly active based graphene cathode for the electro-fenton reaction. RSC Adv. 2015, 5, 42536-42539. [CrossRef]

17. Kong, N.; Liu, J.Q.; Kong, Q.S.; Wang, R.; Barrow, C.J.; Yang, W.R. Graphene modified gold electrode via $\pi-\pi$ stacking interaction for analysis of $\mathrm{Cu}^{2+}$ and $\mathrm{Pb}^{2+}$. Sens. Actuators B 2013, 178, 426-433. [CrossRef]

18. Wonsawat, W.; Chuanuwatanakul, S.; Dungchai, W.; Punrat, E.; Motomizu, S.; Chailapakul, O. Graphene-carbon paste electrode for cadmium and lead ion monitoring in a flow-based system. Talanta 2012, 100, 282-289. [CrossRef] [PubMed]

19. Yang, G.H.; Cao, J.T.; Li, L.L.; Rana, R.K.; Zhu, J.J. Carboxymethyl chitosan-functionalized graphene for label-free electrochemical cytosensing. Carbon 2013, 51, 124-133. [CrossRef]

20. Liu, Y.L.; Chen, W.H.; Chang, Y.H. Preparation and properties of chitosan/carbon nanotube nanocomposites using poly(styrene sulfonic acid)-modified CNTs. Carbohydr. Polym. 2009, 76, 232-238. [CrossRef]

21. Afkhami, A.; Moosavi, R.; Madrakian, T.; Keypour, H.; Ramezani-Aktij, A.; Mirzaei-Monsef, M. Construction and application of an electrochemical sensor for simultaneous determination of $\mathrm{Cd}(\mathrm{II}), \mathrm{Cu}(\mathrm{II})$ and $\mathrm{Hg}$ (II) in water and foodstuff samples. Electroanalysis 2014, 26, 786-795. [CrossRef]

22. Bao, Q.L.; Zhang, H.; Yang, J.X.; Wang, S.; Tang, D.Y.; Jose, R.; Ramakrishna, S.; Lim, C.T.; Loh, K.P. Graphene-polymer nanofiber membrane for ultrafast photonics. Adv. Funct. Mater. 2010, 20, 782-791. [CrossRef]

23. Le, T.X.H.; Bechelany, M.; Lacour, S.; Oturan, N.; Oturan, M.A.; Cretin, M. High removal efficiency of dye pollutants by electron-Fenton process using a graphene based cathode. Carbon 2015, 94, 1003-1011. [CrossRef]

24. Sun, T.; Xu, P.X.; Liu, Q.; Xue, J.; Xie, W.M. Graft copolymerization of methacrylic acid onto carboxymethyl chitosan. Eur. Polym. J. 2003, 39, 189-192. [CrossRef]

25. Tung, V.C.; Allen, M.J.; Yang, Y.; Kaner, R.B. High-throughput solution processing of large-scale graphene. Nat. Nanotechnol. 2009, 4, 25-29. [CrossRef] [PubMed]

26. Ma, J.K.; Wang, X.R.; Liu, Y.; Wu, T.; Liu, Y.; Guo, Y.Q.; Li, R.Q.; Sun, X.Y.; Wu, F.; Li, C.B.; et al. Reduction of graphene oxide with l-lysine to prepare reduced graphene oxide stabilized with polysaccharide polyelectrolyte. J. Mater. Chem. A 2013, 1, 2192-2201. [CrossRef]

27. Li, D.; Mueller, M.B.; Gilje, S.; Kaner, R.B.; Wallace, G.G. Processable aqueous dispersions of graphene nanosheets. Nat. Nanotechnol. 2008, 3, 101-105. [CrossRef] [PubMed]

28. Villar-Rodil, S.; Paredes, J.I.; Martínez-Alonso, A.; Tascon, J.M.D. Preparation of graphene dispersions and graphene-polymer composites in organic media. J. Mater. Chem. 2009, 19, 3591-3593. [CrossRef]

29. Wang, X.; Zhi, L.J.; Tsao, N.; Tomovic, Z.; Li, J.L.; Mullen, K. Transparent carbon films as electrodes in organic solar cells. Angew. Chem. 2008, 120, 3032-3034. [CrossRef]

30. Dubin, S.; Gilje, S.; Wang, K.; Tung, V.C.; Cha, K.; Hall, A.S.; Farrar, J.; Varshneya, R.; Yang, Y.; Kaner, R.B. A one-step, solvothermal reduction method for producing reduced graphene oxide dispersions in organic solvents. ACS Nano 2010, 4, 3845-3852. [CrossRef] [PubMed]

31. Paredes, J.I.; Villar-Rodil, S.; Solis-Fernandez, P.; Martinez-Alonso, A.; Tascon, J.M.D. Atomic force and scanning tunneling microscopy imaging of graphene nanosheets derived from graphite oxide. Langmuir 2009, 25, 5957-5968. [CrossRef] [PubMed]

32. Han, D.X.; Han, T.T.; Shan, C.S.; Ivaska, A.; Niu, L. Simultaneous determination of ascorbic acid, dopamine and uric acid with chitosan-graphene modified electrode. Electroanalysis 2010, 22, 2001-2008. [CrossRef]

33. Stankovich, S.; Dikin, D.A.; Piner, R.D.; Kohlhaas, K.A.; Kleinhammes, A.; Jia, Y.Y.; Wu, Y.; Nguyen, S.T.; Ruoff, R.S. Synthesis of graphene-based nanosheets via chemical reduction of exfoliated graphite oxide. Carbon 2007, 45, 1558-1565. [CrossRef]

34. Konkena, B.; Vasudevan, S. Covalently linked, water-dispersible, cyclodextrin: Reduced-graphene oxide sheets. Langmuir 2012, 28, 12432-12437. [CrossRef] [PubMed]

35. Sreedhar, B.; Aparna, Y.; Sairam, M.; Hebalkar, N. Preparation and characterization of HAP/carboxymethyl chitosan nanocomposites. J. Appl. Polym. Sci. 2007, 105, 928-934. [CrossRef]

36. Jin, M.H.; Kim, T.H.; Lim, S.C.; Duong, D.L.; Shin, H.J.; Jo, J.W.; Jeong, H.K.; Chang, J.; Xie, S.S.; Lee, Y.H. Facile physical route to highly crystalline graphene. Adv. Funct. Mater. 2011, 21, 3496-3501. [CrossRef] 
37. Travlou, N.A.; Kyzas, G.Z.; Lazaridis, N.K.; Deliyanni, E.A. Functionalization of graphite oxide with magnetic chitosan for the preparation of a nanocomposite dye adsorbent. Langmuir 2013, 29, 1657-1668. [CrossRef] [PubMed]

38. Khomyakov, P.A.; Giovannetti, G.; Rusu, P.C.; Brocks, G.; Brink, J.V.D.; Kelly, P.J. First-principles study of the interaction and charge transfer between graphene and metals. Phys. Rev. B 2009, 79, 195425. [CrossRef]

39. Sun, W.; Guo, Y.Q.; Ju, X.M.; Zhang, Y.Y.; Wang, X.Z.; Sun, Z.F. Direct electrochemistry of hemoglobin on graphene and titanium dioxide nanorods composite modified electrode and itselectrocatalysis. Biosens. Bioelectron. 2013, 42, 207-213. [CrossRef] [PubMed]

40. Wang, Z.M.; Guo, H.W.; Liu, E.; Yang, G.C.; Khun, N.W. Bismuth/polyaniline/glassy carbon electrodes prepared with different protocols for stripping voltammetric determination of trace $\mathrm{Cd}$ and $\mathrm{Pb}$ in solutions having surfactants. Electroanalysis 2010, 22, 209-215. [CrossRef]

41. Lin, M.; Hu, X.; Ma, Z.; Chen, L. Functionalized polypyrrole nanotube arrays as electrochemical biosensor for the determination of copper ions. Anal. Chim. Acta 2012, 746, 63-69. [CrossRef] [PubMed]

42. Yuan, X.J.; Chai, Y.Q.; Yuan, R.; Zhao, Q.; Yang, C.L. Functionalized graphene oxide-based carbon paste electrode for potentiometric detection of copper ion(II). Anal. Methods 2012, 4, 3332-3337. [CrossRef]

43. Qiu, S.Y.; Xie, L.D.; Gao, S.; Liu, Q.D.; Lin, Z.Y.; Qiu, B.; Chen, G.N. Determination of copper(II) in the dairy product by an electrochemical sensor based on click chemistry. Anal. Chim. Acta 2011, 707, 57-61. [CrossRef] [PubMed]

44. Zhang, P.H.; Dong, S.Y.; Gu, G.Z.; Huang, T.L. Simultaneous determination of $\mathrm{Cd}^{2+}, \mathrm{Pb}^{2+}, \mathrm{Cu}^{2+}$ and $\mathrm{Hg}^{2+}$ at a carbon paste electrode modified with ionic liquid-functionalized ordered mesoporous silica. Bull. Korean Chem. Soc. 2010, 31, 2949-2954. [CrossRef]

45. Etienne, M.; Bessiere, J.; Walcarius, A. Voltammetric detection of copper(II) at a carbon paste electrode containing an organically modified silica. Sens. Actuators B 2001, 76, 531-538. [CrossRef]

(C) 2016 by the authors; licensee MDPI, Basel, Switzerland. This article is an open access article distributed under the terms and conditions of the Creative Commons by Attribution (CC-BY) license (http://creativecommons.org/licenses/by/4.0/). 